\title{
Tuberculosis axillary lymph node coexistent breast cancer in adjuvant treatment: case report
}

\author{
Tuberculose linfonodal axilar coexistente com carcinoma mamário \\ em tratamento adjuvante: relato de caso
}

\author{
Silvio Eduardo Bromberg ${ }^{1}$, Paulo Gustavo Tenório do Amaral ${ }^{1}$
}

\begin{abstract}
Coexistence of breast cancer and tuberculosis is rare. In most cases, involvement by tuberculosis occurs in axillary lymph nodes. We report a case of a 43-years-old patient who had undergone adenomastectomy and left sentinel lymph node biopsy due to a triple negative ductal carcinoma. At the end of adjuvant treatment, the patient had an atypical lymph node in the left axilla. Lymph node was excised, and after laboratory analysis, the diagnosis was ganglion tuberculosis. The patient underwent treatment for primary tuberculosis. The development of these two pathologies can lead to problems in diagnosis and treatment. An accurate diagnosis is important to avoid unnecessary surgical procedures.
\end{abstract}

Keywords: Tuberculosis, lymph node; Axilla/pathology; Breast neoplasms/ diagnosis; Breast neoplasms/therapy; Chemotherapy, adjuvant; Case reports

\section{RESUMO}

A coexistência de câncer de mama e tuberculose é rara. Na maioria das vezes, 0 acometimento pela tuberculose ocorre nos linfonodos axilares. Relatamos caso clínico de paciente de 43 anos submetida à adenomastectomia e à biópsia de linfonodo sentinela à esquerda devido a um carcinoma ductal triplo negativo. Ao final do tratamento adjuvante, a paciente apresentou linfonodomegalia atípica em axila esquerda. Foi realizado exérese do linfonodo e, após análises laboratoriais, diagnosticou-se tuberculose ganglionar. A paciente foi submetida a tratamento para tuberculose primária. 0 desenvolvimento dessas duas patologias pode acarretar problemas quanto ao diagnóstico e ao tratamento. 0 diagnóstico acurado é importante para evitar procedimentos cirúrgicos desnecessários.

Descritores: Tuberculose dos linfonodos; Axila/patologia; Neoplasias da mama/diagnóstico; Neoplasias da mama/terapia; Quimioterapia adjuvante; Relatos de casos

\section{INTRODUCTION}

Breast tuberculosis was first described by Astley Cooper in 1829 who called it scrofulous swelling of the bosom. The coexistence of primary tuberculosis and breast cancer was reported only in 1897 by Pilliet and Piatot, and the tuberculosis of axillary lymph nodes was reported by Warthin in 1899. ${ }^{(1)}$ The coexistence of these two morbidities is extremely rare and ranges between 0.1 to $4.9 \%$. Most of reports are related with compromised axillary lymph nodes due to tuberculosis injury, which might coexist or not along with neoplastic injury. ${ }^{(2)}$

The diagnosis of compromised ganglion by tuberculosis is difficult because of its rare clinical manifestation. In general, this disease manifests with isolated lymphadenomegaly or associated with few and unspecific symptoms such as high fever and weight loss. These symptoms can also be seen in cases of advanced breast cancer or locoregional recurrence of breast cancer. ${ }^{(3)}$ During the treatment for breast cancer, the ganglion tuberculosis is normally associated with immunosuppression status, which is eventually correlated with the chemotherapy treatment applied to control neoplastic disease. ${ }^{(4,5)}$

We report a case of patient with breast cancer who developed tuberculosis in ipsilateral axillary lymphadenomegaly and who had undergone adjuvant treatment. A diagnosis dilemma occurred due to the possible locoregional recurrence of breast cancer.

\section{CASE REPORT}

A 43-years-old white woman RAS was admitted with palpable nodules in the left breast for at least 6 months.

1 Hospital Israelita Albert Einstein, São Paulo, SP, Brazil.

Corresponding author: Silvio Eduardo Bromberg - Avenida Albert Einstein, 627/701, room 122C, building A1 - Morumbi - Zip code: $05652-900$ - São Paulo, SP, Brazil - Phone: (55 11) 2151-5122 E-mail: sbromberg@einstein

Received on: Aug 27, 2013 - Accepted on: Abr 22, 2014

DOI: 10.1590/S1679-45082015RC2963 
She denied other complaints, history or previous contact with bacillus of tuberculosis. Her only history was treatment for catscratch disease in left side of the body 9 years ago.

Physical examination showed hardening nodules of $15 \mathrm{~mm}$ wide in the junction of lateral quadrants (JLQ) in left breast. Bilateral axillary was palpable. A digital bilateral mammogram was conducted showing only irregular nodules of $14 \mathrm{~mm}$ wide in the JLQ toward the left side. The magnetic nuclear resonance identified irregular nodules of $18 \mathrm{~mm}$ wide in the JLQ toward the left side, close to the chest muscle and $6 \mathrm{~cm}$ away from papillae with heterogeneous enhancement and type 2 curve. In addition, we observed ipsilateral axillary lymphadenomegaly. A biopsy was conducted using an ultrasound guided thick-needle showing invasive ductal cancer of histologic and nuclear grade 3 , triple negative.

The patient underwent adenomastectomy and sentinel lymph node biopsy in left side, associated with immediate breast reconstruction using abdominal muscle flap and breast prosthesis. The anatomopathological result was invasive ductal carcinoma, measuring $17 \mathrm{~mm}$ wide, triple negative and without compromised lymph node. Final staging: T1cN0.

During systemic staging, thoracic-abdominal tomography and bone scintigraphy were normal. Subsequently, the adjuvant systemic treatment for 12 weeks was initiated with four cycles of doxorubicin $60 \mathrm{mg} / \mathrm{m}^{2}$ and $600 \mathrm{mg} / \mathrm{m}^{2}$ cyclophosphamide, followed by $80 \mathrm{mg} / \mathrm{m}^{2}$ paclitaxel.

After chemotherapy treatment, the patient showed fibroblastic nodule of $3 \mathrm{~cm}$ wide, palpable and pain in the left axillary line anterior. The axillary ultrasonography showed irregular nodule calcifications in between, measuring $3.1 \mathrm{~cm}$ wide. The computed tomography revealed enlarged left axillary lymph node containing calcifications (Figure 1). Nuclear resonance showed the same nodule with globose morphology, and area of liquefaction and post-contrast heterogeneous enhancement, measuring $3 \mathrm{~cm}$ wide (Figura 2). A puncture was done using a fine needle and suspected result was reactive lymphadenopathy with fat replacement.

Because a different result was found in puncture and imaging exams, we conducted exeresis of lymph node and anatomopathologic test. The result was chronic inflammatory process associated with granuloma formation and central necrosis (Figures 3 and 4). We also conducted an investigation for Bartonella immunoglobulin due to patient's previous catscratch disease, and the result was negative. In addition, an investigation of tuberculosis complex based on quantitation of interferon gamma was done. The result was positive and suggested the

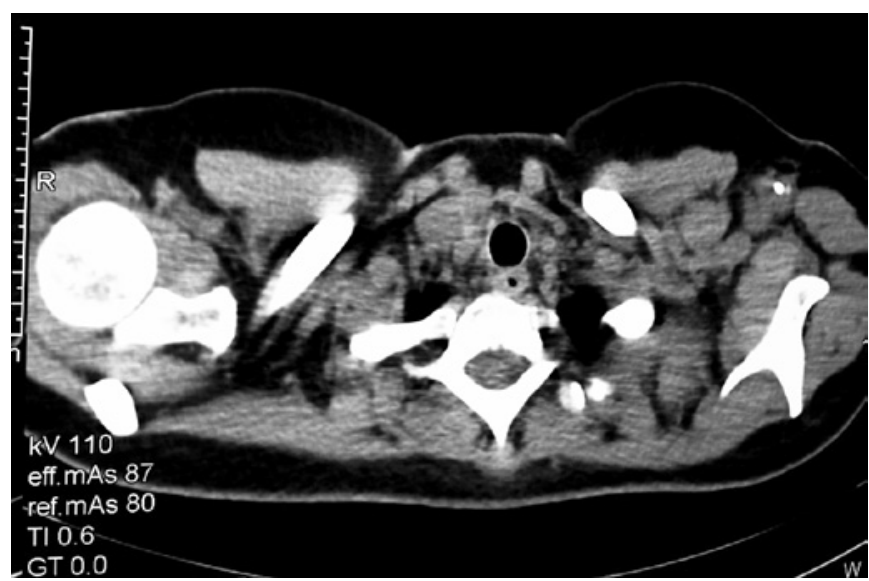

Figure 1. Computed tomography imaging of augmented left axillary lymph node with calcifications

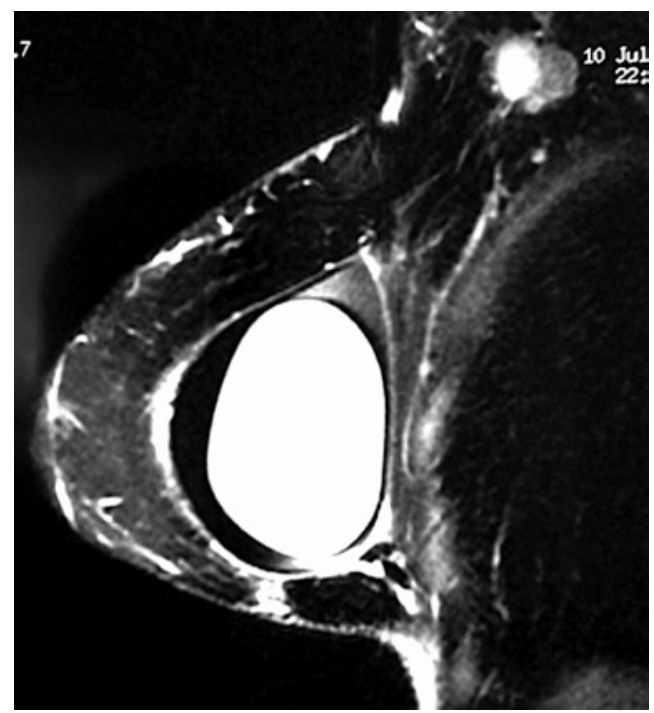

Figure 2. Magnetic nuclear resonance imaging of suspected enhancement of left axillary lymph node

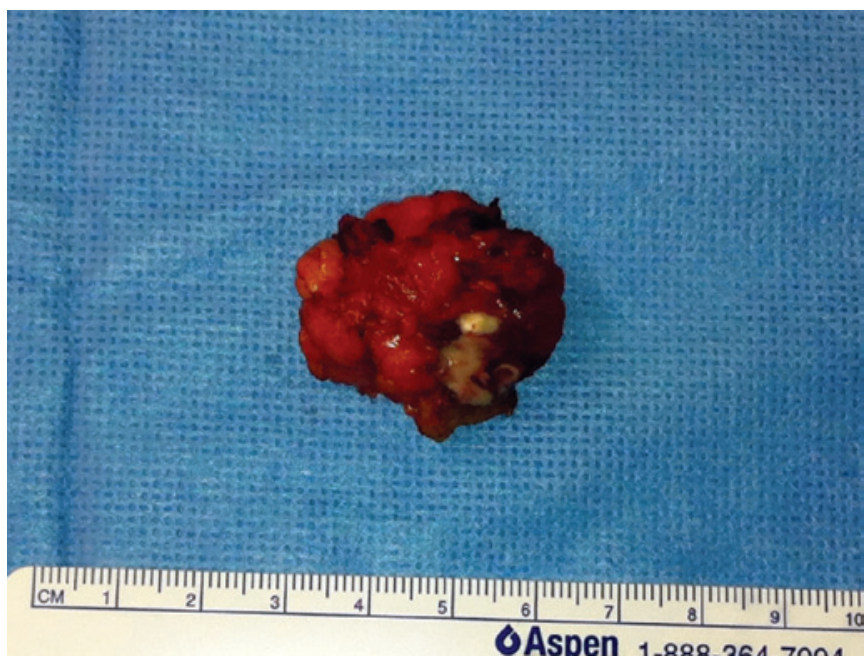

Figure 3. Surgical piece of axillary lymph node 


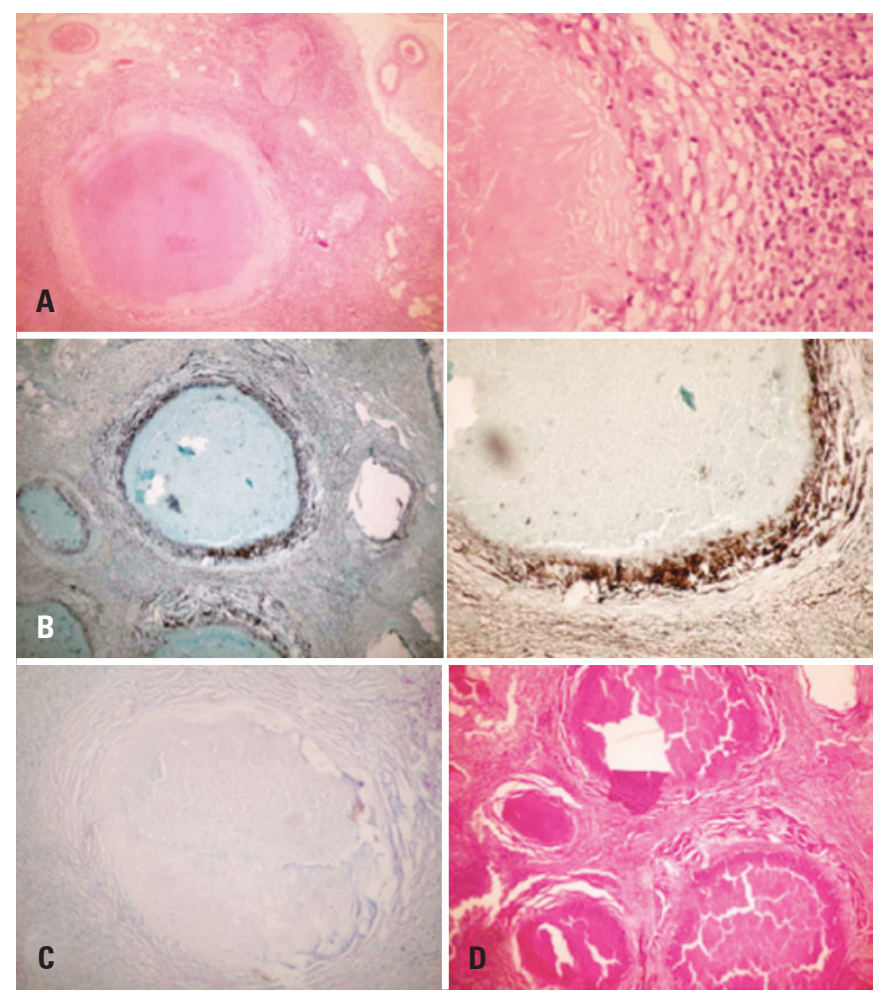

(A) hematoxylin-eosin (routine); (B) Grocott (fungi and yeast); (C) Ziehl-Neelsen; (D) periodic acid-Schiff.

Figure 4. Anatopathological slides with specific staining

diagnosis of tuberculosis of axillary adenopathy. After assessment by an infectologist and positive culture for tuberculosis, the treatment for primary tuberculosis was initiated and the patient remained asymptomatic.

\section{DISCUSSION}

Tuberculosis constitutes a public health problem in several countries. It is estimated that one fifth of the world population has tuberculosis and every year 3 million people die due to tuberculosis. And, even with all diagnostic technology and new treatments available, this number can still increase each year. ${ }^{(6)}$

The association of tuberculosis with breast cancer is rare, ranging between 0.1 to $4.9 \%$. The great percentage of this incidence is because of compromised ganglion in tuberculosis.

To diagnose compromised ganglion in clinical practice, we opted for imaging exams (mammography, ultrasonography and nuclear magnetic resonance), fine-needle aspiration scintigraphy and exeresis of the lesion. Accuracy of these procedures is $14 \%, 12 \%$ and $60 \%$, respectively. To increase diagnosis rate, we used immunology and molecular biology tests that included the use of marked antibodies, immunoenzimatyc assays and polymerase chain reaction. ${ }^{(7)}$

Imaging exams do not enable a distinction between benign and malignant process in such cases, however, images indicating calcifications and liquenification process can lead to suspicion of tuberculosis.

Histologically, the granulomatous inflammatory process and necrosis focus require investigation for tuberculosis independently of the technique used. ${ }^{(8)}$

The treatment of ganglion tuberculosis comprises in the administration of antituberculin drugs (riphampicin, isoniazid, pirazinamid and ethambutol). ${ }^{(3)}$

\section{CONCLUSION}

The appropriate diagnosis of compromised ganglion in tuberculosis coexisting with breast cancer is extremely important to avoid incorrect staging of breast cancer as locally advanced and, in this way, to avoid aggressive surgical axillary treatment for these patients. Therefore, special attention must be given to histopathological investigation of uncommon axillary lymph nodes before definitive surgical treatment.

In addition, in situations where granulomas with caseous necrosis are found in axillary lymph nodes, tuberculosis must be excluded as the main diagnosis. In such cases, an investigation must be done even in asymptomatic patients or those who do not have contact with smear-positive patients, especially because this disease is frequent and histopathological findings resemble tuberculosis.

\section{REFERENCES}

1. Miller RE, Salomon PF, West JP. The coexistence of carcinoma and tuberculosis of the breast and axillary lymph nodes. Am J Surg. 1971;121(3):338-40.

2. Salemis NS, Razou A. Coexistence of breast cancer metastases and tuberculosis in axillary lymph nodes-a rare association and review of the literature. Southeast Asian J Trop Med Public Health. 2010;41(3):608-13.

3. Silva Junior CT. Abordagem diagnóstica da tuberculose pleural, ganglionar, renal e sistema nervoso central. Pulmão (Rio de Janeiro). 2012;21 (1):32-5.

4. Baslaim MM, Al-Amoudi SA, Al-Ghamdi MA, Ashor AS, Al-Numani TS. Case report: breast cancer associate with contralateral tuberculosis of axillary Iymph nodes. World J Surg Oncol. 2013;11:43.

5. Khurram M, Tariq M, Shahid P. Breast cancer with associated granulomatous axillary lymphadenitis: a diagnostic and clinical dilemma in regions with high prevalence of tuberculosis. Pathol Res Pract. 2007;203(10):699-704.

6. Tulasi NR, Raju PC, Damodaran V, Radhika TS. A spectrum of coexistent tuberculosis and carcinoma in the breast and axillary lymph nodes: report of five cases. Breast. 2006;15(3):437-9.

7. Akbulut S, Sogutcu N, Yagmur Y. Coexistence of breast cancer and tuberculosis in axillary lymph nodes: a case report and literature review. Breast Cancer Res Treat. 2011;130(3):1037-42. Review.

8. Walsh N, Greene J, Catherine Lee M. Tuberculous adenopathy masquerading as locally advanced breast cancer. Breast J. 2013;19(1):106-7. 